\title{
Apoptosis y cáncer
}

\author{
Apotosis and cancer
}

Eva M. Molina-Trinidad ${ }^{a}$, Marco A. Becerril-Flores ${ }^{b}$, José L. Imbert-Palafox $^{c}$.

\begin{abstract}
:
Worldwide, it is known that cancer is a disease where there is no control of cell proliferation and the only way to regulate it is through the apoptosis mechanism. The apoptosis process, is also known as programmed cell death and is genetically regulated by cell signaling, likewise, it is part of the mechanism of cell cycle functionality. Furthermore, cancer cells frequently have the ability to evade apoptosis, despite the damage, due to the presence of a protein known as p53 that checks that the genetic material of cells is not damaged (by cell stress or radiation ionizing). The initiation phase of apoptosis is initiated by intracellular or extracellular stress when there are low levels of oxygen or damage to deoxyribonucleic acid or DNA occurs. The implementation phase of this mechanism is performed by enzymes called caspases that cause DNA damage, reorganize the cytoskeleton, and interrupt intracellular transport, cell division, and the translation signal. Various disorders and pathologies are related to the apoptosis process, such as in cancer, where a process of cellular degeneration is involved. In this sense, uncontrolled cell proliferation manifests itself, due to mutations that can be identified in expression, overexpression, or lack of gene expression. Likewise, the treatments to fight cancer are diverse related to the protein balance in the apoptosis process.
\end{abstract}

\section{Keywords:}

Apoptosis, cancer, protein, deoxyribonucleic acid

\section{Resumen:}

A nivel mundial es conocido que el cáncer es una enfermedad donde no existe control de la proliferación celular y la única vía de regular la misma es mediante el mecanismo de apoptosis. El proceso de apoptosis, también es conocido cómo muerte celular programada y se regula genéticamente mediante señalización celular, así mismo, forma parte del mecanismo de la funcionalidad del ciclo celular. Por otra parte, las células cancerosas con frecuencia tienen la habilidad de evadir la apoptosis, a pesar del daño, debido a la presencia de una proteína conocida cómo p53 que revisa que el material genético de las células no esté dañado (por estrés celular o radiación ionizante). La fase de iniciación de la apoptosis es iniciada por estrés intracelular o extracelular cuando existen bajos niveles de oxígeno o se presentan daños en el ácido desoxirribonucleico o ADN. La fase de ejecución de este mecanismo se realiza por enzimas llamadas caspasas que causan daños en el ADN, reorganizan el citoesqueleto e interrumpen el transporte intracelular, la división celular y la señal de traducción. Diversos trastornos y patologías se relacionan con el proceso de apoptosis, cómo en el cáncer, donde se involucra un proceso de degeneración celular. En este sentido se manifiesta proliferación celular sin control, debido a mutaciones que se pueden identificar en la expresión, sobreexpresión o en la falta de expresión genética. Así mismo los tratamientos para combatir el cáncer son diversos relacionado con el balance proteínico en el proceso de apoptosis.

\section{Palabras Clave:}

Apoptosis, cáncer, proteína, ácido desoxirribonucleico

\section{Introducción}

El término "apoptosis" proviene del Griego apo (desde) y ptosis (cayendo) o caída de los pétalos de una flor. ${ }^{1,2} \mathrm{En}$ los diferentes tejidos que conforman nuestro organismo

\footnotetext{
a Autor de Correspondencia, Universidad Autónoma del Estado de Hidalgo, https://orcid.org/0000-0001-9654-5918, Email: eva_molina8849@uaeh.edu.mx

b Universidad Autónoma del Estado de Hidalgo, https://orcid.org/0000-0002-2322-4686, Email: mbecerril_65@yahoo.com

c Universidad Autónoma del Estado de Hidalgo, https://orcid.org/0000-0002-2931-4375, Email: imbertox@ hotmail.com
} 
existe un equilibrio homeostático entre la producción de células nuevas mediante el mecanismo de división celular, y la muerte celular es un proceso de renovación celular. Los mecanismos de división celular y de muerte celular son controlados por eventos especializados. El mecanismo conocido cómo muerte celular programada hace alusión a la apoptosis, el cual es propiamente un mecanismo programado de importancia para el desarrollo embrionario y para proceso por el cual se destruyen axones y dendritas de las sinapsis neuronales con el fin de eliminar las neuronas extra y sus conexiones aumentando la eficiencia de las transmisiones neuronales. ${ }^{3,4}$

Se conocen dos fases en la apoptosis: la fase de iniciación y la de ejecución. La fase de iniciación involucra proteínas con funciones diferentes y se puede manifestar de forma intracelular y extracelular. Este evento ocurre fisiológicamente durante la morfogénesis, la renovación tisular y en la regulación del sistema inmunitario. Eventos celulares específicos pueden ser explicados por trastornos en la regulación de los genes responsables de la apoptosis como en la progresión tumoral.

Por otra parte, la apoptosis es un fenómeno biológico, permanente, dinámico e interactivo. Por mencionar algunos eventos biológicos que desencadenan apoptosis son las señales extracelulares, pérdida de factores de crecimiento, disminución en los niveles de oxígeno y la radiación. Dentro de las señales intracelulares conocidas se menciona ADN dañado, la quimioterapia como consecuencia de daño generado por la administración de fármacos y el mal funcionamiento de los telómeros y la infección por virus. ., 6

\section{Concepto de apoptosis}

Los patrones de muerte son reproducibles de acuerdo a estudios realizados con embriones de pollo ${ }^{7}$. Se consideró como muerte celular programada (MCP) a la función celular controlada genéticamente según estudios realizados en insectos. 8,9

\section{Clasificación de apoptosis}

Los primeros estudios de morfología para clasificar los fenotipos de muerte celular se basan en la identificación de tres tipos de muerte celular: Tipo 1,2 y $3 .^{10}$

\section{Muerte celular tipo 1}

Se manifiesta por condensación nuclear y picnosis, con reducción del volumen citoplasmático, con fragmentación celular tardía y fagocitosis.

\section{Muerte celular tipo 2.}

También conocida como degeneración autofágica, se caracteriza por la vacuolización autofágica del citoplasma.

\section{Muerte celular tipo 3.}

También conocida como muerte citoplasmática, se caracteriza por una desintegración general con pérdida de los organelos. Los tres eventos se muestran en la Figura 1.

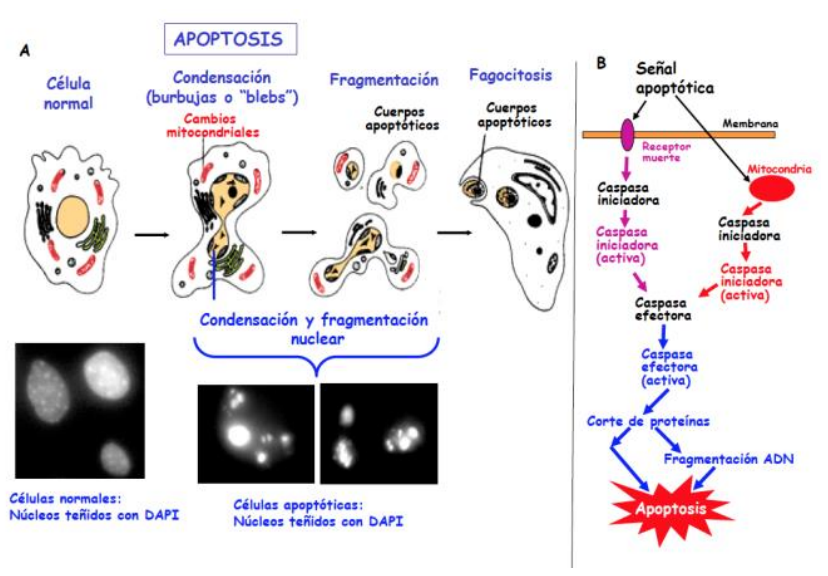

Figura 1. A) Proceso de muerte celular por apoptosis: condensación de los diferentes organelos celulares, fragmentación celular generando cuerpos apoptóticos y fagocitosis. Parte inferior: Imágenes del microscopio óptico mostrando núcleos teñidos con DAPI (4,6 diamidino2-fenil-indol, tinte fluorescente del ácido nucleico) de células normales o apoptóticas donde los núcleos aparecen condensados o fragmentados. B)

Rutas de activación de la apoptosis: de receptores de muerte y mitocondrial. Cascadas de activación de caspasas que conducen a la ruptura de proteínas y a la activación de la fragmentación de $A D N^{11}$.

En los años 90s se clasifico la MCP en dos subtipos: $3 \mathrm{~A}$ o desintegración no lisosomal y la 3B citoplasmática. $^{12}$ Actualmente la MCP tipo 3 se conoce como Necrosis (la necrosis se caracteriza por el edema celular con ruptura de la membrana). Un ejemplo de necrosis celular se muestra en la Figura 2.

En general, se ha encontrado que el fenotipo dominante se manifiesta por la velocidad relativa del programa de muerte. Hoy en día la Biología Molecular se encarga de encontrar marcadores moleculares que coadyuven a la identificación de los tipos de muerte celular. 


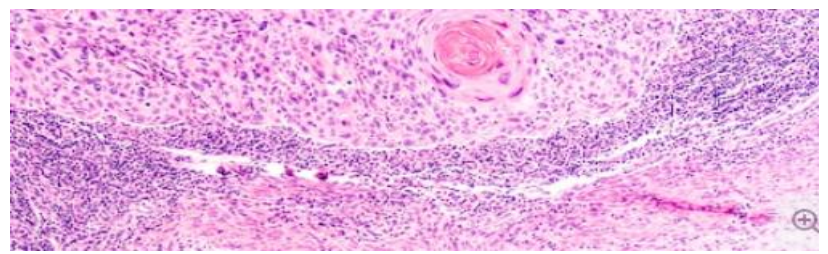

Figura 1. Cáncer cérvico-uterino. Imagen histológica de células invasivas escamosas de carcinoma asociada con displasia escamosa (CIN III, HSIL: alto grado de lesiones intraepiteliales), relacionada con el virus del papiloma humano (HPV).

\section{Características de la apoptosis}

Los procesos bioquímicos de la apoptosis incluyen el núcleo celular, ya que, en este orgánulo se encuentran genes que codifican para proteínas encargadas de autodestruir a las células cuando la célula se ve afectada por estímulos exógenos que afectan la vida celular. De esta forma, cuando las células sufren apoptosis, su tamaño disminuye y su núcleo se condensa. Durante el desarrollo de la apoptosis, el núcleo celular y la célula se fragmentan, y los restos celulares son fagocitados por los macrófagos que reconocen proteínas de superficie. Eventos aunados a la apoptosis, es la fragmentación de ADN en sitios nucleosomales. Este mecanismo se da por acción de enzimas conocidas cómo endonucleasas específicas. Los eventos anteriores representan el patrón de degradación internucleosomal de ADN, que es un evento común en todos los eventos de apoptosis, cómo es el caso del endometrio uterino, las células granulosas, el epitelio prostático y las células mamarias. ${ }^{1}$ En la siguiente tabla se muestran algunos ejemplos de células y tejidos en donde la apoptosis se encuentra asociada con la degradación de ADN.

Tabla 1. Ejemplos de células y tejidos, donde el proceso de apoptosis se asocia con la degradación de ADN.

\begin{tabular}{|l|l|}
\hline Tejido/Células & Activador \\
\hline Timocitos & $\begin{array}{l}\text { Glucorticoides Antireceptor } \\
\text { de linfocitos T }\end{array}$ \\
\hline Timocitos & Ionóforos de calcio \\
\hline Linfocitos & Toxina de la Difteria \\
\hline Epitelio uterino la la & Ovariotomía \\
\hline $\begin{array}{l}\text { Células lúteas y de } \\
\text { granulosa }\end{array}$ & Gonadotropina \\
\hline Próstata & Castración \\
\hline Células cancerosas & Antiestrógenos \\
\hline Células mamarias & Antiprogestinas \\
\hline
\end{tabular}

\section{Mecanismo de formación}

La relación de la apoptosis con el ciclo celular es determinante cómo proceso opuesto a la división celular. En el ciclo celular hay cuatro fases: mitosis (M), fase de control celular G1, síntesis de ADN (S) y fase de control G2. La apoptosis puede iniciarse en el tercio final de G1 para impedir que una célula dañada ingrese a la fase de síntesis de manera que las mutaciones no se reproduzcan durante la replicación del ADN y en la fase G2 para evitar que las células que no hayan llegado a la madurez ingresen a la fase de mitosis.

Los complejos proteicos formados por subunidades conocidas como ciclinas y quinasas dependientes de ciclinas (CDK) son los promotores de la división celular. Las CDK son sintetizados por genes específicos, y se sintetizan de manera continua dada su inestabilidad. En el paso de la fase G1 a la S, actúa la ciclina $D$ asociada a las quinasas ciclinodependientes 2,4 y 6 (cdk 246 ).

En la segunda mitad de la etapa G1, aumenta la cantidad la ciclina $\mathrm{E}$ con la quinasa ciclinodependiente 2 . En la fase de síntesis actúa la ciclina A con CDK 2 y en la fase G2, la ciclina B con CDK 2. En la fase G1 se presentan dos puntos importantes: G0 (en la mitad de la fase) donde el ciclo puede detenerse y la célula bloquea su crecimiento pero se mantiene ejerciendo su proceso metabólico y un punto de restricción (en unión de los 2/3 con 1/3 final de esta fase) para detener el ciclo y corregir defectos celulares (de su ADN). Si no hay reparación se induce el mecanismo de muerte celular. ${ }^{13}$

En la fase G2 también existen elementos de detección de inmadurez celular que inducen la apoptosis cuando la célula no está preparada para ingresar en mitosis, por lo cual, durante el ciclo celular se determina cuando la célula ingresa en el proceso de autodestrucción, o bien puede continuar el ciclo celular y dividirse, entonces se lleva a cabo un balance entre mitosis y apoptosis, regulando la población celular de cada tejido. En el proceso de apoptosis actúan enzimas conocidas cómo complejo de cisteína-aspartato proteasas (caspasas). Se conocen a la fecha 11 caspasas en células humanas que provocan una degradación proteica bien definida formando cuerpos apoptóticos. Algunas caspasas son "iniciadoras" y otras "efectoras" del proceso catalítico, actuando sobre endonucleasas que son las responsables directas de la fragmentación del ADN. La cadena de degradación proteica tiene sucesivos clivajes dependientes de la ubicación del ácido aspártico que se repite en la estructura de la enzima. Existen hasta 40 sustratos en la catálisis según reportes científicos. Existe la participación de varios complejos moleculares en la activación de las caspasas cómo pro-caspasas inactivas. 


\section{Vía extrínseca}

La vía extrínseca conocida como "receptores de muerte" establece conexiones con el espacio extracelular, recibiendo señales proapoptóticas desde el exterior y de las células circundantes. Receptores involucrados en este proceso son la proteína Fas y el factor de necrosis tumoral (TNF). La proteína transmembrana Fas en su porción intracelular enlaza con un factor intermedio denominado FADD (factor associated death domain), nombre que sólo señala que está comprometido con la zona de la molécula Fas que participa en la muerte celular, activando las caspasas 8 y 10. Si la parte interna de la molécula se asocia con otro factor llamado DaXX, se activan las enzimas proteín-kinasas que conducen a la estimulación en el ciclo celular y al proceso de division cellular conocido como mitosis. Esta vía Fas permanece inactiva hasta que se produce en su parte externa el enlace con un cofactor llamado ligando Fas, proteína que actúa como detonador donde las caspasas están inactivas y el resto de la cadena está preparado para recibir el enlace exterior. Con el receptor de membrana TNF, su función radica en que su porción intracelular se conecta con complejos intermedios como el Tradd (TNF receptor associated death domain) y Raidd (receptor associated interleukine death domain) que activan caspasas "iniciadoras" de la apoptosis.

Con otro complejo llamado Traf (TNF receptor associated factor) activan proteín- kinasas y estimulan la proliferación celular. Las caspasas cortan en sistios específicos a proteínas que reorganizan la estructura del citoesqueleto como Gas2, fodrina y Btubulina. ${ }^{14}$

\section{Vía mitocondrial}

Existen otras vias de inducción de apoptosis como la vía mitocondrial. En este proceso intervienen las proteínas de la familia de $\mathrm{Bcl}-2$ que regulan la apoptosis ejerciendo su acción sobre la mitocondria. La activación de proteínas pro-apoptóticas de la familia de Bcl-2 produce un poro en la membrana externa de las mitocondrias que permite la liberación de numerosas proteínas del espacio intermembranal como el citocromo C. El citocromo $\mathrm{C}$ en el citosol, activa un complejo proteico llamado "apoptosoma", que activa directamente a la caspasa-9; que a su vez activa a las caspasas efectoras como la caspasa-3, lo que desencadena las últimas fases de la apoptosis.

Por otra parte, el gen bcl-2 forma parte de una familia de genes que intervienen en la regulación de la supervivencia de la célula. Los miembros de la familia Bcl2 están integrados por: Bcl-2, Bax, Bad, Bcl-X1, Bcl-Xs, Mcl-1. La función celular está determinada por las diferencias en la expresión de estas proteínas, actuando algunas como promotoras y otras como inhibidoras de las señales de apoptosis. Las proteínas de la familia de Bcl-2 se agrupan en tres familias: la familia de las proteínas antiapoptóticas (Bcl-2, Bcl-Xl, Mcl-1 y otras); la familia de proteínas proapoptóticas de tipo "multidominio" (Bax y Bak) y las proteínas proapoptóticas de tipo "BH3-only" (Bid, Bim, Bad y otras). Las proteínas tipo multidominio pueden producir poros por si solas en liposomas, lo que indica que probablemente son suficientes para formar el poro mitocondrial que permite la liberación del citocromo C. Las proteínas tipo BH3 activan estas proteínas, y las antiapoptóticas inhiben la formación del poro.

Por otra parte, una vez activado el apoptosoma, la cliva activa a la procaspasa $3 \mathrm{~b}$ y a la caspasa 3 conocida como caspasa efectora. Así mismo en la salida de citocromo $\mathrm{C}$ desde la mitocondria, otra proteína llamada SMAC/DIABLO actúa como inhibidor de los inhibidores de caspasas (IAPS). En la siguiente figura se observa el ordenamiento, oligomerización y autoproteólisis de las caspasas clase I para su activación.

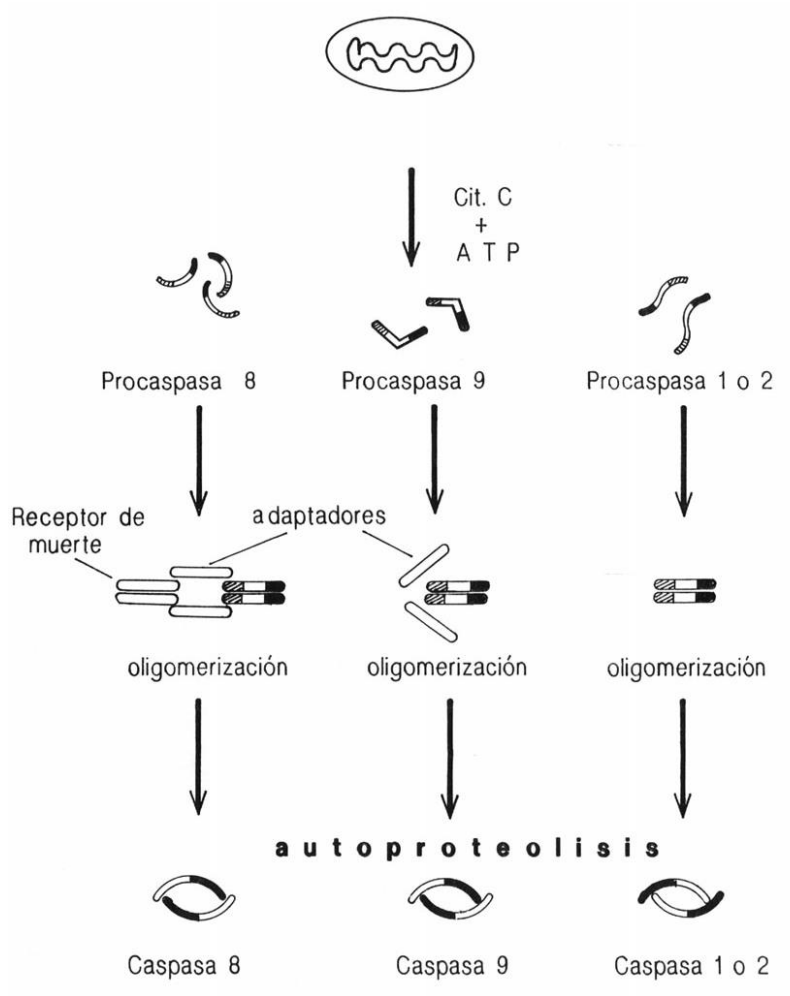

Figura 3. Cuándo se recibe una señal de muerte las procaspasas de clase I pueden interaccionar con los adaptadores para su ordenamiento y activación (caspasa8). Otras señales liberan citocromo $C$ de mitocondria con dATP que se une a Apaf-1 activando a la enzima caspasa9. Las pro-caspasas 1 y 2 no necesitan adaptadores para su activación. ${ }^{14}$ 
En esta vía la caspasa efectora no actúa, porque sus inhibidores fueron evitados por SMAC/DIABLO y la apoptosis se presenta de forma natural.

El Bcl-2 se expresa de manera importante durante estadios muy tempranos de la diferenciación de células $B$ y $T$, y también está altamente expresado en la etapa de diferenciación final de los linfocitos; es por ello que las células en estadios intermedios de desarrollo son más susceptibles a la muerte celular.

La Bcl-2 no confiere protección a la célula contra la apoptosis, ni en la selección negativa de células autorreactivas del timo, ni en los mecanismos citotóxicos de los linfocitos T citotóxicos (CTL). Tampoco se aprecia su efecto protector sobre las células $B$ inmaduras que sufren apoptosis por entrecruzamiento $\operatorname{lgM}$ ni en la activación de la célula vía receptor Fas/TNF.

La vía mitocondrial puede conectarse también con la vía de receptores de muerte, ya que una vez activada la caspasa-8 por dichos receptores, esta caspasa activa a la proteína Bid, lo que provoca la apertura del poro mitocondrial y la activación de la caspasa-9.

Se dice que el heterodímero Bcl-2Bax y la variante $\mathrm{Bcl}-\mathrm{X} 1$ tienen efecto inhibitorio de la muerte celular, al impedir la acción de las proteasas cisteínas que median señales de apoptosis, pero la formación de homodímeros Bax-Bax, así como elevados niveles de Bax o Bcl-Xs, pueden favorecer la muerte programada de la célula. ${ }^{15}$

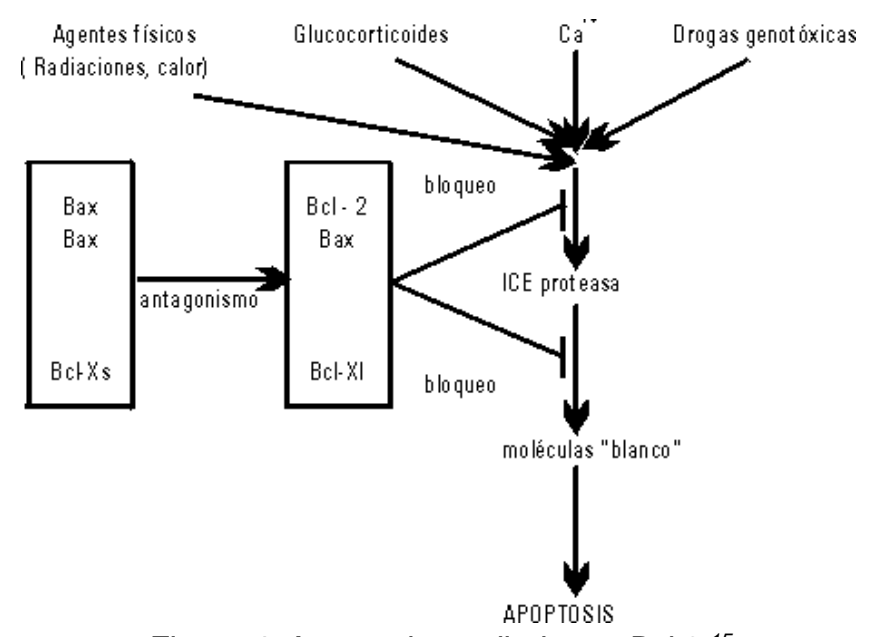

Figura 4. Apoptosis mediada por Bcl-2. ${ }^{15}$

\section{Otras vías}

Oncogenes y genes supresores de tumor forman parte en el mecanismo de muerte celular programada; tal es el caso de los genes c-myc y nur- que estan relacionados con la progresión del ciclo celular y participan en la inducción de apoptosis en algunas células, también se encuentra el gen Bcl-2 y actuan bloqueando el proceso de apoptosis.

El gen p53, cuyo requerimiento se produce en casos de daño genómico puede inducir cáncer a la apoptosis. Esto sugiere que la muerte celular programada se presenta como un mecanismo de defensa contra la transformación en muerte celular. El gen p53 ha sido llamado guardián del genoma por ser el encargado de bloquear la división celular cuando las células han sufrido daño en el ADN, se encuentra en el brazo corto del cromosoma 17 (17p13), codifica un factor de transcripción nuclear de 43.7 KDa. Este mecanismo se da en la fase G1 del ciclo celular, con el fin de que se produzca la reparación del $A D N$ antes de que se replique. Este gen mantiene la integridad del genoma ya que estimula la apoptosis en las células en las que el daño en el DNA se ha manifestado. En diversas células cómo en los linfocitos, la sobreexpresión del gen p53 conduce directamente a la apoptosis.

La proteína codificada por el gen supresor de tumor p53, es una fosfoproteína que se localiza en el núcleo celular. Cuándo se dio a conocer, se creía que el gen p53 era un oncogén. Se demostró que la forma mutante de p53 es responsable de bloquear la división celular de células dañadas y que la forma salvaje suprime la transformación.

El gen p53 efectúa el control del ciclo celular en el paso de $\mathrm{G} 1$ a $\mathrm{S}$ en el proceso de división celular. Cuando se han producido lesiones en el ADN, el gen p53 actúa en el ciclo celular en G1-S para dar tiempo a que actúen los sistemas de reparación del ADN y de esta forma mantiene la integridad genómica; la reparación y síntesis del ADN; la diferenciación celular; la represión de la transcripción; la plasticidad genómica y la apoptosis.

La forma salvaje de p53 actúa como un gen supresor de tumor recesivo. Se descubrió que la forma mutante del gen p53 tiene las características de un oncogén dominante. Actualmente se dice que la mutación en p53 es uno de los cambios genéticos más frecuentemente encontrados en el cáncer humano. La función del gen p53 es importante para mediar el desarrollo de cáncer, por esta razón actúa como un gen supresor de tumor. La proteína p53 está presente en pocas cantidades en el organismo y cuando las células son expuestas a estímulos genotóxicos, los niveles de p53 se elevan y se inicia la muerte celular mediada por la regulación de la transcripción. ${ }^{16}$

Estudios reportados en el 2009, hacen alusión a la función del p53 con los telómeros que conforman los extremos de los cromosomas y en participación de la reprogramación de células troncales y en células que presentan daño en el ADN o presentan mecanismos de reparación de mismo. ${ }^{17,18}$ 


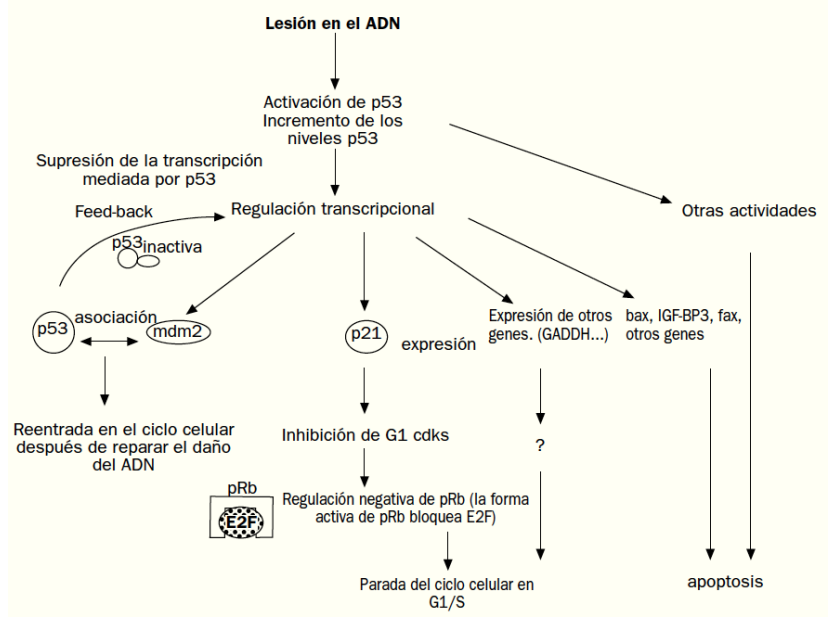

Figura 5. Función del gen p53 en el control de la progresión del ciclo celular. ${ }^{16}$

\section{Relación clínica de la apoptosis}

Es conocido que los seres vivos mantienen su especie por medio de división celular, y estos procesos terminan cuando por alguna alteración fisiológica se manifiesta la muerte celular. En mamíferos se produce por necrosis, auto-fagia o apoptosis. La apoptosis es, un proceso fisiológico de eliminación celular regulado y caracterizado por una secuencia de cambios morfológicos: contracción celular, condensación de la cromatina y fragmentación nuclear y celular, con formación de cuerpos apoptóticos ${ }^{5}$. En el desarrollo del cáncer y su tratamiento juega un papel importante la apoptosis. La alteración genética de las células tumorales induce a la muerte por apoptosis, pero este proceso puede sufrir cambios genéticos con las proteínas relacionadas. En las células cancerosas la apoptosis puede ser, un fenómeno reversible, las células tumorales apoptóticas podrían tener efectos inmunomoduladores, induciendo alergia o fenómenos inmunosupresores y en insuficiencias cardíacas congestivas, aterosclerosis y aneurismas. ${ }^{19}$

Por otra parte el desarrollo de resistencia a la muerte celular ha sido reconocido como uno de los mecanismos básicos durante el desarrollo del cáncer y, sus vías, se presentan como dianas terapéuticas.

Un gen asociado a la pérdida de la función normal de la célula es el gen p53 que puede conducir al desarrollo de cánceres humanos (más del $50 \%$ de los tumores humanos están asociados a mutaciones en p53).

Otros estudios sugieren la influencia de la expresión de nur77 en la proliferación o la diferenciación celular que actúa como un factor de transcripción que regula la expresión genética involucrados en la muerte celular.

Otro regulador fisiológico del ciclo celular que participa en la apoptosis es la proteína Myc, que es producto del proto-oncogen c-myc. La sobreexpresión del gen c-myc pudiera resultar en mitosis o apoptosis en dependencia de la disponibilidad de otros factores que estimulan el crecimiento celular. Así, la expresión incrementada de $\mathrm{Bcl}-2$ en presencia de c- myc produce una inhibición de la apoptosis mediada por c-myc, lo que explica la cooperación que se produce entre ambos genes en el origen de las neoplasias.

De esta forma, la apoptosis en el origen del cáncer se ve controlada por la misma enfermedad como en la interrupción de la hematopoyesis en síndromes mielodisplásicos. ${ }^{20}$

Finalmente se mencionan las enfermedades relacionadas con el proceso de apoptosis como el cáncer, malformaciones, trastornos metabólicos, neuropatías, lesiones cáncer, malformaciones, trastornos metabólicos, neuropatías, lesiones miocárdicas y trastornos del sistema inmunitario.

Enfermedades asociadas a inhibición de apoptosis son: Cáncer: linfoma no Hodgkin folicular (Bcl-2 +), carcinoma (p53 +), tumores hormono-dependientes.

Enfermedades auto inmunitarias: lupus eritematoso sistémico, glomerulonefritis auto inmunitaria.

Infecciones virales: Herpes virus, Poxvirus, Adenovirus

\section{Enfermedades asociadas a aumento de apoptosis:} Inmunodeficiencia adquirida (Sida)

Enfermedades neurodegenerativas: enfermedad de Alzheimer, enfermedad de Parkinson, esclerosis lateral amiotrófica, retinitis pigmentosa, degeneración cerebelosa.

Síndromes mielodisplásicos (MDS): anemia aplástica Daño isquémico: infarto de miocardio, apoplejía, daño por reperfusión, daño hepático por alcoholismo.

Hepatocarcinogenésis: la apoptosis, necroptosis, piroptosis y ferroptosis son los tipos de muerte celular explorados durante el daño en tejidos, y diferentes tipos de muerte de hepatocitos eventualmente conducen a diferentes tipos de cáncer de hígado. Por mencionar la necroptosis de los hepatocitos incuba un ambiente que determina el crecimiento del colangiocarcinoma intrahepático $(\mathrm{CCl})$, pero si los hepatocitos se encuentran en el entorno creado por los hepatocitos apoptóticos, tienden a convertirse en HCC8. Por otra parte, la deleción específica de hepatocitos de la subunidad NEMO / IKKY de la quinasa IKB (IKK) sensibiliza la apoptosis de los hepatocitos por inhibición de NF-kB, que forma espontáneamente HCC comprobado en estudios en ratones de 12 meses. ${ }^{21}$ Otras proteínas que regulan la apoptosis de los hepatocitos, como la quinasa 1 activada por TGF- $\beta$ (TAK1), el factor 2 asociado al receptor de TNF 
(TRAF2) y la subunidad beta de la quinasa IKB (IKK $\beta$ ), también participan en la hepatocarcinogénesis. la apoptosis de los hepatocitos es fundamental en el inicio de la hepatocarcinogénesis, y los mecanismos reguladores moleculares de la apoptosis de los hepatocitos y sus funciones en la hepatocarcinogénesis es objeto de estudio actual. ${ }^{22}$

\section{Conclusión}

La apoptosis es una forma de muerte celular programada que tiene una via extrínseca relacionada con los receptores de la muerte (Fas y el factor de necrosis tumoral TNF); y una via intrínseca relacionada con la familia Bcl-2, involucrada con la eliminación de tejidos dañados, evitando la proliferación de células cancerosas.

Este mecanismo es importante en el desarrollo embrionario como mecanismo morfogenético que permite la homeostasis y que mantiene el número de células en cada tejido, regulando así mismo el sistema inmunitario mediante la eliminación de las células T que no reconocen antígenos extraños y a las células $T$ que reconocen antígenos propios con alta afinidad, relacionadas con diversas enfermedades como el cáncer.

\section{Referencias}

[1] Cáceres CJR. Cáncer y apoptosis. Vertientes. Revista Especializada en Ciencias de la Salud. 2003; 6(1-2): 8-14.

[2] Wong RS. Apoptosis in cancer: from phatogenesis to treatment. J. Exp. Clin. Cancer Res. 2011; 30:87.

[3] Cools R, Barker AR, Sahakian JB, RobbinsnTW. Mechanism of cognitive set flexibility in Parkinson's disease. Brain. 2001; 124: 2503-2512.

[4] Rochon D, Rousse I, Richard R. Synapse-Glia Interactions at the Mammalian Neuromuscular Junction. The Journal of Neuroscience. 2001; 21(11):3819-3829.

[5] Kroemer G, Galluzzi L, Vandenabeele P, Abrams J, Alnemri ES, Baenhrecke EH, et al. Classification of cell death: recomendations of the nomenclature. Committee on Cell Death. 2009; 16:3-11.

[6] Cohen, JJ, Duke, RC. Apoptosis and programmed cell death in inmmunity. Annu Rev Inmmunol. 1992; 10:267-293.

[7] Saunders JW Jr, Gasseling MT. Cellular death in morphogenesis of the avian wing. Dev Biol. 1962; 5:147-78.

[8] Lockshin RA, Williams CM. Programmed cell death-I. Cytology of degeneration in the intersegmental muscles of the pernyi silkmoth. J Insect Physiol. 1965; 11:123-33.
[9] Kerr JF, Wyllie AH, Currie AR. Apoptosis: a basic biological phenomenon with wide-ranging implications in tissue kinetics. Br.J.Cancer. 1972; 26: 239-257.

[10] Schweichel JU, Merker HJ. The morphology of various types of cell death in prenatal tissues. Teratology. 1973; 7(3):253-66.

[11]Almudena PI. Apoptosis: una forma controlada de muerte celular. SEBBM Divulgación. La Ciencia al alcance de la mano. 2010. Revisada el 27 de abril del 2020 en: https://www.sebbm.es/archivos_tinymce/mayo2010_almudenaporrasi sabelmarzo.pdf

[12] Clarke PG. Developmental cell death: morphological Diversity and multiple mechanisms. Anat Embryol (Berl). 1990;181(3):195-213.

[13] Desaher S, Martinas JC. Mitochondria as the central control point of apoptosis. Trends Cell Biol. 2010; 10(9). Recuperado de http://www.ncbi.nlm.nih.gov/publimed.

[14] Elinos-Báez CM, Maldonado V, Meléndez-ZajglaJ. Caspasas: moléculas inductoras de apoptosis. Gac Méd Méx. 2003; 139(5): 493 499.

[15] Pérez, MJ, Lie AEC. Apoptosis: Revista de Ciencias Médicas de la Habana. 2012; 18(2):1-6.

[16] López M, Anzola M, Cuevas-Salazar N, Martínez de Pancorbo. P53, un gen supresor tumoral. Gac Med Bilbao. 2001; 98(1):21-27.

[17] Marion RM, Strati K, Li H, Murga M, Blanco R, Ortega S, et al. A p53-mediated DNA damage response limits reprogramming to ensure iPS cell genomic integrity. Nature. 2009; 460:1149-1153.

[18] Salamanca-Gómez F. Células troncales, cáncer y p53. Gac Méd Méx. 2009; 145(5): 441-442.

[19] Díez J. Apoptosis en las enfermedades cardiovasculares. Rev Esp Cardiol. 2000; 53: 267-274.

[20] Rothstein G. Disordered Hematopoiesis and Myelodysplasia in the Elderly. J Am Geriat Soc. 2003; 51(3): 22-26.

[21] Green D. R. The coming decade of cell death research: five riddles. Cell 177. 2019; 1094-1107.

[22] Schneider, A. T. et al. RIPK1 suppresses a TRAF2-dependent pathway to liver cancer. Cancer Cell. 2017; 31, 94-109 